DOI: 10.20472/IAC.2018.042.043

\author{
KATE SATO \\ Hokkaido University of Science, Japan \\ TOSHIYUKI SAKABE \\ Hokkaido University of Science, Japan
}

\title{
TO WHAT EXTENT IS THE COURSE EXPERIENCE QUESTIONNAIRE APPLICABLE TO JAPANESE EDUCATION?
}

\begin{abstract}
:
With a shift towards global education and 'world-class' universities, reliable methods to measure the quality of courses becomes more pertinent. The quality of Japanese higher education has been questioned. Simultaneously, the quality assessment system in Japanese higher education has been called fragmented. The Course Experience Questionnaire (CEQ) is recognised as a statically reliable and valid tool for assessing the efficacy of courses and is used in higher education in many countries around the world including Australia and the UK. Therefore, there is potential for its use in Japanese institutions. However, it is based on Western concepts of student learner theories. Confucian values influence Japanese education. Therefore, the extent to which the CEQ could be applicable for use in Japanese higher education requires examining. However, this remains largely unexplored. In this paper first, Japanese academia is examined using two constructs: 1. Hofstede's cultural dimensions, and 2. a Confucian framework. The findings are then used to examine concepts within the CEQ, to unearth their applicability within Japanese education. This study reveals there are potentially complex ramifications related to implementing the CEQ as a tool for measurement in Japanese higher education. Further research into student learner theories in a Japanese context is recommended to find a way forward for global assessment in higher education.
\end{abstract}

\section{Keywords:}

culture, international universities, course evaluation, CEQ, cultural dimensions, Confucius, Japan.

JEL Classification: 129, 120, F01 


\section{Introduction}

Since 2008 discussions on global higher education have been the topic of academic papers. In Japan, the government took measures to create an internationalized core (Burgess, Gibson, Klaphake and Selzer, 2010) through the Top Global 30 project. Hatoyama (Prime Minister of Japan from 2009 to 2010) took initiatives so credits from Japanese universities could be transferred with universities overseas. Pouring 15 billion yen into the Global 30, the aim was to welcome more overseas students in Japanese universities.

Twenty years on and with efforts made by the Japanese government to encourage globalization in Japanese higher education, a slow shift away from traditional trends is emerging in the 37 universities participating in the Top Global 30 project (Rose and McKinley, 2018). Ritsumeikan, a private university in the Top Global 30 project, aims to further themselves as a top global university and has set targets for 2023 which include increasing the number of: full-time international faculty and students who study abroad during their time at the university, as well as increasing the number of international students. However, in the 2018 Times higher education rankings Ritsumeikan, considered as one of Japan's top private universities, is ranked 801 out of 1,000. Even Japan's highest ranking university, Tokyo University, is ranked number 46 . With increasing competition in the global market, how can university courses be evaluated from a culturally unbiased perspective?

Kitamura said that until the 1970s there was 'no comprehensive higher education policy' in Japan (1997:141). However, in the OECD member countries a move towards increased accountability in higher education triggered increased accountability in public spending. Emerging from this came the move in some departments of some universities to invite external reviewers, and course evaluations by students (Kitamura, 1997). However, in a culture such as the Japanese where maintenance of the 'wa' or harmony is critical in order to maintain the collective unity, questions such as, 'who were the reviewers', and 'how valid was the data from the students?' arise. Nevertheless, PI based on global scales will be needed in higher education.

Although the Japanese government is taking initiatives to create a more global higher education in Japan, the situation of Japanese higher education has been documented and Japanese higher education has become the subject of discussion and concern. McVeigh (2015) highlights some of the realities in Japanese higher education putting the blame on the political and corporate establishments that are buried in layers of cultural history and practices. In his critique, he laments over the 'ritualization' (2015:144-145), the entrance exams and 'exam hell (ibid.: 247). However, he fails to address the reasons behind such practices and the sweeping generalisations made in his book. Rituals and 
hard work are part of the Japanese ethos, and this is explained below. However, the discussion given below only offers an explanation as to why change is coming slowly to Japanese higher education, it does not solve the more pertinent issue of global assessment in higher education.

From the late 1990s increased efficiency in Japanese higher education has been sought (Arimoto, 1997). This desire is now coupled with the concept of 'global universities.' This study explores concepts in Japanese academia using Hofstede's cultural dimensions and a Confucian framework. From that foundation, the applicability of the concepts in the CEQ can then be reviewed. Therefore, a Confucian framework is discussed first in order to highlight their impact revealed through Hofstede's cultural dimensions, after which the concepts in the CEQ are discussed.

\section{Confucian Framework}

Although some scholars (such as Paramore) argue that Confucianism in post-war Japan had a 'limited social impact' (2016, p.167), many attest to the fact that the moral and ethical influences that have run so long and deep in Japanese culture have not been erased like they may have been from the textbooks. The influence of Confucianism remains a part of the Japanese culture: Reischauer and Jansen state, 'Confucian ethical values continue to permeate their thinking' (1995, p.204). The way in which the Japanese mind set has remained influenced is of pertinence to this paper and we will look at some factors including 'interpersonal relations and loyalties, and faith in education and hard work; (ibid). The influence of Confucianism in Japanese education not only lies in the 'ivory towers of academia' (Paramore: 2016, p. 167) but also in 'basic education' (Tu: 1996, p.172) and daily life.

As with any philosophy there are threads that are woven together to make the tapestry of Confucianism. We can examine them individually, but it is important to remember they are closely interconnected. For example, the concept of personhood. In Confucianism, the relationships, and thus interactions a person has, brings forth personhood (Lai, 2018). Impacting personhood are the roles of a person in society. Intertwined are the ethics and morality of the person. In Confucianism practice is important. It is one thing to learn about conducting oneself in a certain way, but more important is learning to conduct oneself in that way. Therefore, in the Japanese education system there is ample opportunity to apply Confucian virtues and put them into practice.

One Confucian virtue that is practiced in Japanese education includes respecting those who are older than you. This includes peers as well as teachers. This is evidenced in the language with use of the words such as 'kouhai' (for a peer in a year below you at school, or in a company) and 'sempai' (for the peer above you) as well as 'sensei' (meaning 
teacher, or doctor). It is this type of relationship that Littlejohn says, 'is derived from the Five Relationships of Confucianism' (2010:164). This respect extends to not asking the teacher question in class, remaining silent, and respectful. Therefore, the teacher-centred classroom is common in Japan, and only in recent years, since MEXT (2013) (The Ministry for Education, Culture, Sports, Science and Technology, Japan) introduced 'active learning' in 2012, has active learning become a buzz word in Japanese higher education and consequently teaching practices have started to shift towards a more student-centred approach.

Self-restraint, or 'gaman' is another virtue found throughout Japanese society including the education system. Interwoven with this is putting the group's interests before your own which in turn helps practice self-restraint thus keeping the harmony of the group. Takai and Ota (1994), in their assessment of interpersonal communication competence in Japan questioned the use of the measuring tools of Western origin. When they used the Japanese interpersonal competence scale, their findings revealed factors of 'Perceptive Ability, Self-Restraint, Social Appropriateness, Interpersonal Sensitivity, and Tolerance for Ambiguity' (ibid). These factors emerge from roots in Confucianism which is explained below. This is one illustration of the difficulty in applying Western tools in Japanese education. There is simply a mismatch.

Peace and harmony are fundamental to Confucianism (Yao, 2004). Permeating daily life in Japan is the desire to keep the peace, and be at harmony with other people. At school children are taught to suppress their individual feelings in order to put those of the group, or class, first. This concept also exists in companies and throughout the Japanese society. Nagamoto recounts a story of a lecturer and the reaction of the president of the university which clearly illustrates the expectation to keep the peace, put others first, and be loyal to the group. The lecturer 'backed out of a lecture she was supposed to take part in' (2012: 144) because it was on a weekend that conflicted with a once-in-a-lifetime family event. The president told her she was acting 'irresponsibly' (ibid). This example highlights the mind-set mentioned above, namely that where interpersonal relations, loyalty and hard work have unsaid cultural expectations, which stem from Confucianism. Littlejohn (2010) also explains how the way of making decisions through consensus is related to 'harmony' or keeping the peace, in Confucianism.

Honesty in the sense of 'truthful, always believable' (Littlejohn, 2010:163), and honour meaning 'good reputation' (ibid) are two other cultural values that are founded in Confucianism. Surprising to some, after the tsunami and disaster in Fukushima in 2011, shops were not ransacked, houses were not looted, items were not stolen. Stories of theft in Japanese public schools are very rare. Being honest and of good reputation are intertwined with relationships, and again the concept of harmony, respect and peace comes back to the essence of personhood. Lebra in explaining about the concept of self 
in the Japanese culture says, 'honesty, sincerity, truthfulness, openness, and so on' (1992:117) are positive outward signs of sacrificial dedication of oneself towards others. Honesty, is therefore a much-desired virtue. The Japanese way of thinking, according to the Japanese scholar Hajime Nakamura (1960) as concluded by Doi (1962) is that 'the Japanese way of thinking is greatly influenced on immediate personal relations' (1962:136).

Having touched on Confucian philosophies such as respect, self-restraint, the strong desire (or perceived need) to keep the peace and harmony of the group with honesty and honour, it is evident how these are woven into the fabric of the Japanese thinking and culture, education system, along with the perception of personhood. With this foundation, Hofstede's cultural dimensions are now discussed.

\section{Hofstede's cultural dimensions}

By investigating the difference in values businessmen from different countries held, Hofstede pursued his investigation which lasted seven years (from 1973-1980) and from which the outcome was four cultural dimensions (Hofstede, 1983). Since then this work has been refined, and today there is the 6-D model (Hofstede Insights, 2018) with six dimensions: power-distance index (PDI), uncertainty avoidance index (UAI), individualism vs collectivism (IDV), masculinity vs femininity (MAS), long-term orientation vs short-term orientation (LTO), and indulgence vs restraint (IND). By examining at each of these, and how Japan compares to other countries, it is possible to see major differences between Japan and Western cultures.

The definition of the power-distance dimension is the extent to which the less powerful members of institutions and organisations within a country expect and accept that power is distributed unequally (Hofstede Insights, 2018). For Japan, the score is mid-way and this can be a little deceptive. This is because while decisions are made on a consensus basis (as mentioned above) there is also great respect for those in authority. It is these two factors that are kept in harmony in the Japanese culture. The outcome of these two dynamics working together means change is a gradual process in the Japanese culture. There is also another reason for change being a slow process, that is the cultural tendency to avoid risk, which is next.

Maintaining harmony underpins the Japanese culture and is the foundation for the high score on the risk avoidance dimension. For harmony to be maintained in the Japanese culture risk need to be minimized. Further evidenced in the Japanese culture, are conflict avoidance and competition; which too contribute to maintaining social harmony. If conflict and competition are reduced then the potential for risk is also reduced. In light of the subject of this paper, at this juncture to imagine an education system, and a classroom 
based on cooperation, reduced competition, and minimal confrontation is to begin to grasp the education system in Japan where debating is a foreign concept, and where sports days in Elementary schools are not about an individual winning but that of your team, and where teachers are respected, and rarely, if ever, questioned by their students. Another reason for avoiding risk is security is increased. Needless to say, the score for Japan on Hofstede's the uncertainty avoidance index score is very high.

Having seen why change is slow, and how relationships are important next the long-term orientation vs short-term orientation is discussed. This dimension is described as how a culture links its past to the present and future challenges (Hofstede Insights, 2018). Japan has a very high long-term index score. This means that the Japanese culture views the present as a moment in comparison to its long existence. Therefore, a longterm perspective is taken on matters, which complements the slow and steady changes that avoid risk and keep the peace with society as a whole. It is such a perspective that helps the Japanese economy remain stable, and Japanese businesses healthy. However, this also means that meeting needs has been equally slow (Hoshi, \& Patrick, 2012). This explains why change in the Japanese education system is gradual, with external trends such as the declining population and an increased global economy being catalysts for government reforms and change.

Before seeking to understand the masculinity - femininity dimension in relation to the Japanese culture, it is important to grasp an understanding of the individualism collectivism index. This dimension evaluates the importance of the individual vis à vis the group in a culture. Compared to western societies Japan shows stronger collectivist tendencies. In reference to Asian students in Hong Kong Kember notes, 'Evidence is presented of a communal nature to achievement motive, which fits well with Confucian tradition' $(2000 ; 101)$. This concept may well be applicable to other cultures influence by Confucianism, including Japan. Achieving is woven into the tapestry of collectivism (and this is illustrated in the following paragraph), however there is another Confucian thread strengthening the collectivist mind-set: loyalty. Clearly visible in the culture has been the loyalty to the family or business, to the extent where suicide has been the more honourable option to losing face and negatively impacting the group. It is loyalty to the group (collectivist) combined with the importance of keeping harmony, and putting the group before oneself that is significantly different in the context of learning in the classroom. In light of this, the masculinity - femininity dimension is now discussed.

Japan is 'one of the most Masculine societies in the world' (Hofstede Insights, 2018) which means competition, success and achievement are valued and respected. Confucian philosophy has certainly influenced Chinese students as hard work, endurance and effort are valued in that culture (Yang, 1986). Therefore, it is possible that the same philosophy has similarly influenced Japanese students who study for long hours after 
school in order to achieve high grades. This desire for success could appear to conflict with the other dimensions, but when firmly embedded in loyalty, harmony, risk avoidance and a long-term perspective it help in laying a solid foundation for Japan's strong economy. How this is evidenced in the education system is of pertinence to this study. In the education system, instead of individuals competing against each other, classes pitch against each other for results on tests, cleanliness of the classroom, and behaviour. Naturally, there may be some friendly rivalry between peers, but this is not purposefully encouraged by the system, or peers. In academic studies, there appears a paradoxical situation. The students strive to do well on tests, but in classroom participation rather than competing with each other they may play down a high ability, knowledge and skills. In other words, involuntary competition exists (students do not volunteer to be a part of the test-taking system that exists in Japanese schools), but involuntary competition is less evident (students will refrain from competing individually in classes as they want to keep the harmony, and don't want to stand out).

The sixth, and final of the cultural dimensions is indulgence - restraint. Japan has more of a 'restraint' culture which means that their individual desires are restrained, and less 'emphasis' is put on satisfying their desires, or on leisure time. Focus is more on work, relations with colleagues at work or school, and on the group one finds oneself in. This concept of putting work over individual desires helps explain the response of the head of the university in Nagamoto's (2012) study mentioned above. It also complements the competitiveness of the IND score, especially in light of the context where groups pitch against each other rather than individuals.

From examining the influences of Confucianism in Japanese culture, the importance emphasised on harmony, loyalty, honesty, relationships and respect has been shown. From Hofstede's cultural dimensions the importance of working together whilst respecting those in authority above you, avoiding risk, focusing on long-term outcomes, competition in a collective sense and being able to restrain yourself and focus on those around you rather than yourself and your own desires, have been discussed. With these factors as a foundation, the CEQ is now examined.

\section{Concepts within the Course Experience Questionnaire}

\section{Background}

Before discussing the constructs, and concepts in the CEQ the background of the CEQ is outlined in order to paint a fuller picture and grasp the wider context of the CEQ.

The CEQ was originally developed in the UK in the 1980s to measure 'differences between academic organisational units in... important aspects of teaching' (Ramsden, 1991:132). It was the result of many years' researching and analysing qualitative data on 
student feedback (ibid.). Trials took place in Australia where results were 'reasonably internally consistent' (ibid.:133) and eventually it went to trial nationally. The CEQ underwent rigorous testing and Ramsden states it is a 'useful instrument for describing important differences in the teaching performance of academic units' (1991: 148).

The questionnaire is multi-purpose; it can reveal the overall satisfaction of the students compared to the course satisfaction. It can also be used to compare departmental results. Furthermore, when administered nationally, and consistently, the survey can reveal trends in the university, and can also be employed for calculating the sector average. Therefore, it is a very attractive tool, especially as there has been increased interest in performance indicators $(\mathrm{PI})$ in higher education in the UK, and other countries.

The CEQ has been found some applicability for use outside Australia and the UK, including Greece (Stergiou \& Airey, 2012), Holland (Jansen, van der Meer \& FookensBruinsma, 2013), Ireland (Byrne \& Flood, 2003) and the West Indies (Steel, West \& Simeon, 2003), however the extent to which is may be applicable in the context of Japanese Universities has been questioned by Fryer et al. as '[t]he purpose and structure of Japanese higher education is sufficiently different from the context of the original validation' (2017:554) who also note that 'Asian students, with their Confucian cultural origins and strong emphasis on memorization starting with early education, may be more likely to apply combinations of Surface and Deep approaches for learning' (ibid.: 558). As the CEQ is based on such approaches, what they are and the validation of this statement needs attention for this study.

Ramburuth and McCormick explain that Briggs's 3P Model 'demonstrates the relationship' (2001:334) between the various factors that influence a learner which are: 'the reasons for learning, contextual components of the learning environment, strategies for engaging learning, and the quality of learning outcomes' (ibid.). In the $3 \mathrm{P}$ Model Briggs explained there were three phases of learning which are called 'presage' (prelearning), process (mid-learning, or learning) and product (post-learning). Ramburuth and McCormick (2001) detail the factors that impact these three phases and explain that it is in the process phase where the following three approaches to learning may take place: Deep, Surface or Achieving.

Given that the CEQ is founded on these precepts, further explanation of these approaches is given. The qualitative research of Marton and Säljö (1976), conducted in a Western context, lay the foundation for the defining the difference between the Deep and Surface approach. It was reported that in the surface approach students were 'trying to memorize words or phrases' (Tweed and Lehman, 2002:13) whereas in the Deep approach students were trying to 'understand the main points, or infer the main meaning' 
(ibid.). The outcome was that the students who used Deep approaches to learning performed more highly than those that used Surface approaches.

The Achieving approach 'refers to students making an effective use of space and time (strategy) in order to maximise grades (-motive) (Biggs, Kember \& Leung, 2001)... the achieving (or strategic) approach indicates how students organise their learning (eg when, where, how long they learn)(Briggs et al., 2001; Lonka et al., 2004)' (Baeten et al, 2010).

Today it is compulsory for courses in Japanese universities to be evaluated. This is accomplished by means of a general questionnaire handed out by the teacher, to the students in the class. The students complete the questionnaire in pencil, colouring the 'lozenges' in a 5 point Likert scale. In some cases, students might write comments on the reverse side of the questionnaire as they are invited to. The teacher is then responsible for collecting in the questionnaires and ensuring they are given to the university for analysis. Anecdotal stories of some teaching staff taking advantage of this system by erasing student answers and pencilling their own are not unheard of. Even in a society where there is a high aversion to risk, and the potential of brining shame on oneself and those connected to you, does not appear to be enough of a deterrent for those who are possibly more ashamed of their lack to yield satisfactory answers from their students from the questionnaire. Certainly, changing to an on-line format (the CEQ can be administered on line) would provide a more direct way of collecting responses.

From the literature, learner approaches are underlying three phases of learning. The three learner approaches, Deep, Surface and Achieving, appear distinct and separate from one another, rather than interlocking or fluid, moving along a spectrum. With the move towards global universities along with having touched on the research from which constructs in the CEQ were created, the items in the CEQ are now examined against the background of Confucianism and Hofstede's cultural dimensions

\section{The items in the CEQ}

There are three versions of the CEQ. They are the CEQ 36, CEQ 30 and CEQ 23 (the number indicates the number of items in the questionnaire). The CEQ 36 consists of six scales which are: the Good Teaching Scale (GTS), the Generic Skills Scale (GSS), the Appropriate Assessment Scale (AAS), the Appropriate Workload Scale (AWS), the Clear Goals and Standards Scale (CGS), and the Emphasis on Independence (INS).

The GTS requires the student to evaluate the work of their teachers, those who are in a position higher than themselves. Evaluating a teacher puts the student in a place where they feel they have the right to comment on aspects of the course, such as the teachers' performance. Wording in the GTS may also suggest that it is the role of the teacher to motivate the student to do their best. As mentioned above, motivation in a culture with 
Confucian influences comes from loyalty and collectivist philosophies. While any teacher can impact the motivation of a student, the following question emerges: should 'good teaching' be defined by the extent to which a teacher motivates their students? Such concepts may be difficult for a Japanese student to grasp.

The GGS measures skills such as teamwork, analytical skills, problem solving, writing, tackling the unfamiliar and planning. Throughout elementary school in Japan children are taught to review and reflect (hansei), work out what they could have done better, so as to plan better next time. This is a skill, or strategy, which they take and use throughout their lives in the culture. As a result of this being an integral part of Japanese education, events are successfully planned to the minute, and public transport runs with punctuality to the second to such extent that headline foreign news reports when a train in Japan leaves 20 seconds (BBC, 2017), or 25 seconds early (BBC, 2018) and apologies are made for this early departure. Through these 'hansei kai' (review discussions) Japanese children learn to analyse, and improve what went before. This is where they learn to appreciate and listen to everyone's contribution so as to find the best way forward. These are the analytical and problem solving skills they learn from a young age which they apply to planning. Furthermore, it is in this process that the risks are minimised and the unfamiliar often averted. As discussed before Japanese are very skilled at minimising risk, and analysing the 'unfamiliar' which until thoroughly examined may hold a plethora of risks. Therefore, how Japanese students would interpret the items on the GSS, and how they would respond, and then how those results are interpreted would require careful contextual analysis.

The Appropriate Workload Scale (AWS) asks the student about their perceptions of the workload of their course. If McVeigh's (2015) accounts of Japanese universities were to be a true for most universities then the results of this scale would be predictable. However, currently in some universities the truth is students have to work hard to complete their workload and graduate successfully, or pass national exams in order to become certified in their field. Regardless of this, and more pertinent is the interpretation of the meaning of the scales. Similar to the other scales, the system, the authorities, and those in respected positions come into question by the students. Not only may students feel uncomfortable being asked to give their opinion on the items, but the data may be compromised because of this.

Clear Goals and Standards Scale (CGS) ask for students to comment within the standard context of the learning. For Japanese students in a Japanese context, the norms with regards to the standard of work expected, the amount of work, the speed of learning and volume of work may be perceived as predetermined with little flexibility. Therefore, the purpose of the questionnaire may be questioned, if not regarded with suspicion. If gathering feedback on such items shows any degree of dissatisfaction, those responsible 
for the design of the curriculum may view this system as questioning those in authority, or even potentially threatening, which could impact the harmony, and even interpersonal relationships. Potential for the afore mentioned could hinder the implementation of the questionnaire, until perceived risks have been eliminated.

The Emphasis on Independence Scale (INS) examines the curriculum content, learning process and assessment modes within the students' learning environment, bound by practical limitations (Wilson et al., 1997). As discussed previously in this paper the learning process of Asian students, including those of Japanese, differ. Choice within a curriculum or course will be predetermined by the establishment. In Western universities sparking the interest of the student through teaching or coursework may be considered the responsibility of the university and faculty, however the extent to which this would be applicable in Japanese universities needs examining. Similarly, choice of how to learn, or what work students' have to complete, would need careful dissemination before determining whether such questions are appropriate to ask the students to answer.

\section{Discussion}

There are a number of issues that emerge through looking at the constructs of the CEQ through the Confucian philosophy and Hofstede's cultural dimensions. By asking to what extent the CEQ could be applied as a tool in Japanese Higher education with a potential need for an assessment tool globally in higher education three main concerns come to light: firstly, concerns with the difference in learner approaches, secondly, environmental concerns including differences in value systems, context and the environment, and thirdly, concerns surrounding the implementation of the CEQ.

From the literature on learner approaches, and Confucianism there are apparent differences in learner approaches. Japanese students can be seen studying late into the night, on trains, and at the authors' current university staying overnight, studying, through the night, especially during the period of exams. This is not to generalise this is the case for all students in Japan, however, this sight is a common occurrence in some Japanese universities. Japanese students are used to working hard, memorising facts, and show great self-discipline in studying. However, if understanding in Japan were to be gained through repetition, as Kember and Gow's (1991) study indicates, it is conceivable that by measuring learning at different points over time the results measured each time would differ. Kember, in a more recent study, stated: 'Evidence of the intention to both understand and memorise has also been found in ...Japan (Hess and Azuma, 1992)' (2000: 104). Could it therefore be that the learning methods in Japan are more fluid or move along a spectrum, rather than being compartmentalised as in the theories used for constructing the CEQ? Kember also states there is 'no foundation' (2000:110) that students in Hong Kong prefer passive learning methods, and this could probably be the 
same for students in other Asian countries (ibid). This is as Fryer (2017) mentioned. It appears Japanese students may use learner approaches that consist of a combination of the Deep, Surface and Achieving Could this memorisation-learning-memorisation cycle, prove more effective to those methods used in Western Universities? Certainly, the PISA results show some indication of this. Consistently Japan has remained in the top 10 for maths, reading and science, and Singapore takes top place for all three. With Asian countries taking the top places in the PISA tables, there may be good reason to not implement a tool based on Western learner approaches. Care is needed when thinking about the impact of using the CEQ, as this could lead to a change in teaching practices if faculty start 'teaching to the test'. There are also other concerns with the implementation of the CEQ, which are addressed after the second concern which is environmental.

Environmental concerns arise from difference in the perception of roles in society, definitions and context. As Ramburuth and McCormick (2001) explain there are relationships between various factors that influence a learner which include: 'the reasons for learning, contextual components of the learning environment, strategies for engaging learning, and the quality of learning outcomes' (2001:334). As stated above the learning outcomes of Japanese students are the envy of those in the West having high PISA scores. Underlying these results are facts that students spend hours memorising to retain information. Fundamental to that is in the role of the teacher and student in Japanese universities and the dynamics of the relationships differ to those in Western universities and, the learning that takes place. Therefore, these need to be examined in context of organisational structure and culture as well as 'the educational and higher education context as well' (Jansen, van der Meer \& Fookens-Bruinsma, 2013).

Japanese culture students respect their teacher as a source of knowledge, to be respected, listened to and not questioned, and they are motivated to do well in their studies, and are mindful of their studying strategies. Therefore, to even question the extent to which your teacher is providing 'good teaching' is to question one that is in authority. Japanese, acknowledge they will always have apart to play in maintaining the harmony by simple fact of their presence being there. Thus, students are more likely question whether they are a good student in the process of determining whether a teacher is a 'good teacher'. Blame, if there is to be any, may be self-inflicted as the student analyses themselves as part of the whole. Further to this, evaluating someone in authority might make some students very uncomfortable. Also, good teaching is a 'complicated matter' (Ramsden, 1991:131) as is defining 'good teaching' (Ramsden, 1991:146) as researchers such as have questioned. Both of these would need to be defined in the Japanese context. What a Japanese student perceives to be a good teacher, or good teaching may differ from those perceptions in the West. Therefore, such 'limitations must be understood' (1991:148) and in addition to the culture, the 'students' perceptions over time' (1991:148) must also be taken into consideration. 
Even suggesting the implementation of the CEQ has implications. Changing the current system of course evaluation would imply that the evaluation system needs improvement. That could further be interpreted that those that made the decision and constructed the current tool did insufficient work. By questioning whether external change is now forcing a review of current practices could be a way forward that is perceived as non-threatening, and keeps the peace. Also, the long-term benefits vs short-term benefits of implementing such a tool would need to be evaluated. How employing such a tool would impact Japanese education also needs very careful consideration. However, the opposite also needs to be asked: if it were not to be implemented how would Japanese universities be impacted?

If the CEQ were to be introduced, as with implementing any change, or 'reform' (McVeigh, 2015) in Japan is that some degree of resistance is to be expected especially as Japan has a high UAI. Resistance may arise from faculty who are comfortable in the way they deliver material. Simultaneously, resistance from students should also be expected, especially in light of Kember's finding where some students were 'inflexible' (2000:111) and 'distrusted' (ibid.) learning methods applied. However, if it is argued that the CEQ is not appropriate for use in Japanese universities because of the difference in learning styles (as mentioned above and which have been influenced by Confucian virtues) this could reduce the opportunity for potential change through using CEQ.

Furthermore, applying a tool such as the CEQ to Japanese students without proper preparation and due consideration of the context within which the learning takes place, and current approaches to learning that are practiced in Japan would be unkind. While the CEQ can provide 'broad brush information on student perceptions' Wilson et al argue that 'such processes often do not provide a sufficiently clear and specific, and motivating, base for the planning of improvements' (1997:46). Diseth (2007) disagrees, stating the results may provide a foundation for providing recommendations for curriculum design and teaching. Clear reasons with convincing evidence would be needed before implementing the CEQ in Japan where risk is avoided, and security, and harmony protected.

As a first step, using the tool, not to gather data with which to predict outcomes, or to be interpreted with the aims or employing the CEQ, but rather to collect data to use as a comparison with Western students might yield interesting results. Nevertheless, methods as outlined in Wilson et al. (1997) would be needed to gather more specific data on students' perceptions related to their learning processes and perceptions of learning in Japanese universities.

Seeing the complexities involved in implementing the CEQ in Japanese universities, the question as to why it should be implemented arises. Therefore, other options, whether 
there are other ways of achieving the same goals, needs thorough investigation. Regardless of what tools, or methods are chosen to appraise, and compare universities globally, they should avoid cultural bias. Undoubtedly this is a difficult task as learning takes place in a context (Ramsden, 2008) but one that needs addressing as external pressures such as global markets and competition is having an impact on education. As Kotter says, 'No one is immune to these forces' (2012:20).

\section{Conclusion}

As there is a shift towards more international education, namely with global universities in Japan, and tools by which to evaluate the universities, such as international university ranking tables, the call for culturally appropriate means with which to get feedback from students about their experiences whilst studying at universities is a growing need.

Japanese ways of thinking and behaving very different to those in the West. They are influenced by Confucian virtues and values that pervade through the society and the education system. Such virtues include respect and loyalty to the group, keeping the harmony and peace in the group, practicing honesty, and self-restraint for the better of oneself in order for the group to benefit.

From Hofstede's cultural dimensions it has been shown that further to the foundations of Confucian values, the outcome results in a culture where risk is minimized, long-term goals are seen as more desirable than short-term goals, for that the Japanese restrain themselves and forgo leisure activities, all whilst working together, keeping the peace, respecting those in authority and collectively having group competition.

The implications of this in the education system have been highlighted. Team spirit, and classroom rivalry, rather than individual achievements, are the main focus in school activities. Respect for those older than you, or in authority, are deeply engrained in the Japanese psyche. At the same time, reaching decisions by consensus maintains the balance of power, and keeps the harmony and peace within Japanese establishments. Simultaneously, honesty, and the absence of crime such as theft are also virtues that are very strong in Japanese schools and universities.

Similarly, the scales need to be contextualized. From a young age, Elementary school children have to learn the Japanese writing system by rote. Mathematics is taught in the same way, memorization. Memorizing facts forms the basis of much of the way in which Japanese children are educated. The outcome is children who become self-disciplined in their studies, through hours of memorization. Through this they also practice self-restraint.

There are apparent differences in learner approaches between students in the West and in Japan. The context is quite different which is evidenced through roles in society, how 
they interrelate, and high scores in the PISA tables. There is also potential danger in implementing the CEQ which will not be welcomed in a culture of risk avoidance.

Caution is advised when tools based on Western concepts are taken without due care and consideration and applied in Japanese higher education. Tools like the CEQ may be widely used in Western cultures, and may even be applicable in Asian cultures, but certainly different results should be expected, and in such cases variation should be welcomed. Research into learner approaches in Japan is recommended and may even be interesting or useful for other countries.

The aim of this paper is not to determine whether something is 'right or wrong' but to add to the evolving process of research by offering a fresh perspective to conundrum of global education where students have increasing mobility to choose where to study. In this paper two constructs, with their evidence, were used to question the extent to which a measuring tool based on Western learner approaches is suitable for use within Japanese higher education, with the underlying question as to how universities can be assessed on a global scale. Education must be viewed with an understanding and appreciation of the context of the culture, regardless of background.

\section{References:}

BAETEN, M., KYNDT, E., STRUYVEN, K. and DOCHY, F., 2010. Using student-centred learning environments to stimulate deep approaches to learning: Factors encouraging or discouraging their effectiveness. Educational Research Review, 5(3), pp.243-260.

BBC, 2017. Apology after Japanese train departs 20 seconds early. Accessed on: https://www.bbc.com/news/world-asia-42009839

BBC, 2018. Japanese train departs early - again. Accessed on: https://www.bbc.com/news/world-asia44149791

BYRNE, M., \& FLOOD, B. 2003. Assessing the teaching quality of accounting programmes: An evaluation of the Course Experience Questionnaire. Assessment \& Evaluation in Higher Education, 28(2), 135145.

DISETH, Å., 2007. Students' evaluation of teaching, approaches to learning, and academic achievement. Scandinavian Journal of Educational Research, 51(2), pp.185-204.

DOI, T., 1962. Amae: A key concept for understanding Japanese personality structure. Japanese culture: Its development and characteristics, (34).

FRYER, L.K., GINNS, P., WALKER, R.A. and NAKAO, K., 2012. The adaptation and validation of the CEQ and the R-SPQ-2F to the Japanese tertiary environment. British Journal of Educational Psychology, 82(4), pp.549-563. 
HESS, R.D. and Azuma, H., 1991. Cultural support for schooling: Contrasts between Japan and the United States. Educational researcher, 20(9), pp.2-9.

HOSHI, T. and PATRICK, H.T. eds., 2012. Crisis and change in the Japanese financial system (Vol. 12). Springer Science \& Business Media.

HOFSTEDE, G., 1983. The cultural relativity of organizational practices and theories. Journal of international business studies, 14(2), pp.75-89.

HOFSTEDE INSIGHTS 2018. Accessed on: https://www.hofstede-insights.com/models/national-culture/

JANSEN, E., VAN DER MEER, J., \& FOKKENS-BRUINSMA, M. 2013. Validation and use of the CEQ in the Netherlands. Quality Assurance in Education, 21(4), 330-343.

KEMBER, D., 2000. Misconceptions about the learning approaches, motivation and study practices of Asian students. Higher education, 40(1), pp.99-121.

KEMBER, D. and GOW, L., 1991. A challenge to the anecdotal stereotype of the Asian student. Studies in Higher Education, 16(2), pp.117-128.

KITAMURA, K., 1997. Policy issue in Japanese higher education. Higher Education, 34(2), pp.141-150.

KOTTER, J.P., 2012. Leading change. Harvard business press.

LAI, K., 2018. Global Thinking. The Philosophers' Magazine, (80), pp.64-69.

LEBRA, T.S., 1992. Self in Japanese culture. Japanese sense of self, pp.105-120.

LITTLEJOHN, R., 2010. Confucianism: an introduction. IB Tauris.

MARTON, F. and SALJO, R., 1976. On qualitative differences in learning: I-Outcome and process. British journal of educational psychology, 46(1), pp.4-11.

MCVEIGH, B.J., 2015. Japanese higher education as myth. Routledge.

MEXT, 2018. Top Global University. Accessed on: https://tgu.mext.go.jp/en/universities/ritsumei/index.html

MEXT, 2013. [学修環境充実のための学術情報基盤の整備について (審議まとめ)] について: 大学図書館の機 能強化に向けて(霞が関だより(第 120 回)). 図書館雑誌, 107(10), pp.632-633.

Accessed on: http://www.mext.go.jp/b_menu/shingi/gijyutu/gijyutu4/031/attach/1336647.htm

NAGAMOTO, D. 2012. Exploring Japanese University English Teachers' Professional Identity, Vol. 23. Bristol: Multilingual Matters.

NAKAMURA, H., 1991. Ways of thinking of eastern peoples: India, China, Tibet, Japan. Motilal Banarsidass Publishe. 
PARAMORE, K., 2016. Japanese Confucianism (Vol. 14). Cambridge University Press.

RAMBURUTH, P. and MCCORMICK, J., 2001. Learning diversity in higher education: A comparative study of Asian international and Australian students. Higher education, 42(3), pp.333-350.

RAMSDEN, P., 2008. The future of higher education teaching and the student experience. The Higher Education Academy. Retrieved March, 30, p.2010.

RAMSDEN, P., 1991. A performance indicator of teaching quality in higher education: The Course Experience Questionnaire. Studies in higher education, 16(2), pp.129-150.

REISCHAUER, E.O. and JANSEN, M.B., 1995. The Japanese today: Change and continuity. Harvard University Press.

ROSE, H. and MCKINLEY, J., 2018. Japan's English-medium instruction initiatives and the globalization of higher education. Higher Education, 75(1), pp.111-129.

STEELE, G.A., WEST, S.A. and SIMEON, D.T., 2003. Using a modified course experience questionnaire (CEQ) to evaluate the innovative teaching of medical communication skills. Education for Health: Change in Learning \& Practice.

STERGIOU, D.P. and AIREY, D., 2012. Using the Course Experience Questionnaire for evaluating undergraduate tourism management courses in Greece. Journal of Hospitality, Leisure, Sport \& Tourism Education, 11(1), pp.41-49.

TAKAI, J. and OTA, H., 1994. Assessing Japanese interpersonal communication competence. The Japanese Journal of Experimental Social Psychology, 33(3), pp.224-236.

Times Higher Education University 2018 rankings accessed on: https://www.timeshighereducation.com/world-university-rankings/2018/worldranking\#!/page/0/length/100/locations/JP/name/hokkaido/sort_by/rank/sort_order/asc/cols/stats

TWEED, R.G. and LEHMAN, D.R., 2002. Learning considered within a cultural context: Confucian and Socratic approaches. American Psychologist, 57(2), p.89.

TU, W.M. ed., 1996. Confucian traditions in East Asian modernity: Moral education and economic culture in Japan and the four mini-dragons. Harvard University Press.

WILSON, K.L., LIZZIO, A. and Ramsden, P., 1997. The development, validation and application of the Course Experience Questionnaire. Studies in higher education, 22(1), pp.33-53.

YANG, K.S., 1986. Chinese personality and its change.

YAO, X., 2004. Conflict, peace and ethical solutions: A Confucian perspective on war. Sungkyun Journal of East Asian Studies, 4(2), pp.89-111. 